\title{
Reduced pollen viability and achene development in Solidago $\times$ niederederi Khek from Poland
}

\author{
Grzegorz Migdałek1*, Jolanta Kolczyk², Artur Pliszko³, Maria Kościńska-Pająk², Aneta Słomka² \\ ${ }^{1}$ Institute of Biology, Pedagogical University of Cracow, Podchorążych 2, 30-084 Cracow, Poland \\ ${ }^{2}$ Department of Plant Cytology and Embryology, Institute of Botany, Jagiellonian University, Gronostajowa 9, 30-387 Cracow, Poland \\ ${ }^{3}$ Department of Plant Taxonomy, Phytogeography and Herbarium, Institute of Botany, Jagiellonian University, Kopernika 27, 31-501 Cracow, Poland
}

\begin{abstract}
Pollen and achene characters of natural interspecific hybrid Solidago ×niederederi Khek were analyzed and compared with putative parental species S. virgaurea L. and S. canadensis L. to estimate the level of disturbances in generative reproduction resulting from its hybrid nature. Pollen viability (stainability) of Solidago $\times$ niederederi from one newly discovered locality in NE Poland was evidently reduced to $\sim 65 \%$ in both viability tests (acetocarmine and Alexander). The diameter of viable pollen (median $21.11 \mu \mathrm{m}$ ) fell between $S$. canadensis (median $19.52 \mu \mathrm{m}$ ) and S. virgaurea (median $23.48 \mu \mathrm{m}$ ). Both parental species produced normally developed achenes with high frequency ( $90 \%)$ whereas in the hybrid, the seed set was dramatically low (6\%). The results clearly indicated that sexual reproduction of hybridogenous taxon $S$. $\times n i e d e r e d e r i$ is disturbed, and its potential impact as an invasive species depends mainly on vegetative propagation.
\end{abstract}

Keywords: pollen grains; pollen viability; acetocarmine test; Alexander test; achene size; Solidago; hybrid

\section{Introduction}

The phenomenon of plant hybridization between alien species and their native congeners that support biotic homogenization significantly reflects global changes in native floras. This process is a major threat to genetic integrity of indigenous plant species [1] and leads to an increase in the number of new taxa which should be characterized as alien plants [2]. The spontaneous occurrence of alien-native hybrids can be very helpful in circumscribing the invasiveness of alien plant species involved in such hybridization. Unfortunately, hybridogenous specimens are often overlooked during the field studies because of the morphological resemblance to their parental species.

In Europe, Solidago $\times$ niederederi Khek, a natural hybrid between the alien $S$. canadensis $L$. and the native $S$. virgaurea L. [3-5] has rarely been recorded in Austria, Denmark, Sweden, Norway, the United Kingdom, Germany, and in Poland [3-13]. Its occurrence is undoubtedly an indirect result of naturalization and invasion of North American S. canadensis $[14,15]$. It is usually intermediate in the shape of inflorescence, the size of the capitulum, and the shape and venation of its leaf $[4,5]$. It has either restricted fertility, able to produce only a few well-developed achenes [4], or

\footnotetext{
* Corresponding author. Email: gmigd@up.krakow.pl
}

Handling Editor: Beata Zagórska-Marek is completely sterile [6]. However, this plant seems to be a long-lived perennial, which forms characteristic clumps of stems like those of $S$. canadensis. There is a need for further research on its vegetative propagation as a way to become established [5]. Solidago $\times$ niederederi grows in open disturbed areas (e.g., abandoned arable fields, quarries, clay pits, railway and river embankments), usually together with the parental species [4-12].

The aim of this work is to confirm the hybrid nature of specimens of $S$. $\times$ niederederi collected from a newly discovered locality in Poland [5] using pollen grain and achene characters. We hypothesized that male meiosis in a hybrid between two Solidago species that are not closely related, becomes disturbed due to the presence of non-homologous genomes. This leads to significantly decreased pollen viability and seed production as compared to its parental species S. canadensis and S. virgaurea.

\section{Materials and methods}

\section{Origin of plant material}

Plants in blooming and fruit development of $S$. virgaurea and S. ×niederederi were collected in September 2011 and identified by Dr. Artur Pliszko in a newly found locality in Mieruniszki village $\left(54^{\circ} 10^{\prime} 43^{\prime \prime} \mathrm{N}, 22^{\circ} 32^{\prime} 04^{\prime \prime} \mathrm{E}\right)$ in the Zachodniosuwalskie Lakeland in NE Poland [5]. The distance between the hybrid plants and parental species did not exceed 
two meters. Individuals of $S$. canadensis were collected in the same season in Balice $\left(50^{\circ} 05^{\prime} 10.3^{\prime \prime} \mathrm{N}, 19^{\circ} 47^{\prime} 01.9^{\prime \prime} \mathrm{E}\right)$ near Kraków (southern Poland) and identified by Dr. Maria Kościńska-Pająk. All analyzed Solidago taxa formed compact belowground rhizome systems developing many genets. For each taxon, pollen grains and achenes were isolated from dry inflorescences of three plants (probably genets).

\section{Estimation of pollen stainability (viability)}

For acetocarmine and Alexander tests, dry pollen grains from 32 flowers of each parental species and from 40 flowers of hybrid S. ×niederederi were shed on slides with drops of $1 \%$ acetocarmine or Alexander's dye [16]. In the acetocarmine test cytoplasm stains red in viable pollen and remains transparent in nonviable pollen, while in the Alexander test viable pollen grains appear red and nonviable pollen grains stain green. Stamens of each flower isolated from inflorescence were divided into two equal parts. Pollen from each part was stained with acetocarmine or with Alexander.

\section{Pollen grain diameter}

Diameter of 500 pollen grains from 32 flowers of each parental species and from 40 flowers of hybrid $S$. $\times$ niederederi was measured under Eclipse E400 optical microscope (Nikon) using NIS Elements (ver. 4.0.) program. Measurements of each grain were performed including exine along polar and equatorial axis.

\section{Achene size}

One hundred achenes of each taxon were used to estimate disturbances in achene development. Length of achenes without pappus was determined on 50 normally developed achenes of both parental species and on 6 well developed achenes of hybrid $S$. ×niederederi. Measurements were carried out under Opta-Tech SK series stereoscopic microscope using OptaView (ver. 7.3.1.7.) program.

\section{Scanning electron microscopy (SEM)}

Dried pollen grains shed directly from inflorescences were dusted onto stubs with SPI carbon-conductive double-sided adhesive discs, sputtered with gold (SPI SUPPLIES ionsputtering system), and observed with a scanning electron microscope (HITACHI S-4700).

\section{Statistics/data analysis}

Comparison of achene size, pollen size, pollen viability between taxa, and both viability tests were conducted using
Kruskal-Wallis ANOVA with Wilcoxon signed rank tests with Bonferroni correction post hoc. Statistical analyses were performed in $\mathrm{R}$ program (ver. 3.1.1.).

\section{Results and discussion}

Interspecific hybrids, especially between species that are not closely related, usually have disturbed generative reproduction due to abnormalities in male (microsporogenesis) and female (macrosporogenesis) meiosis. Such abnormalities result from the presence of non-homologous chromosomes in the hybrid genome as was observed in several interspecific Viola hybrids [17-20].

Disturbances might also accompany female and male gametophyte embryo and endosperm development, leading to reduced seed set or even total sterility [17-22]. Two putative parental species, $S$. canadensis and $S$. virgaurea, which belong to different sections - Unilaterales and Solidago, respectively (cf. Pliszko[5] and references therein), are diploid, karyologically uniform and have a somatic chromosome number $2 \mathrm{n}=18$ [23]. Solidago $\times$ niederederi described from many localities in Europe [3-13] and found in one locality in Poland [5] is most likely diploid with the same chromosome number $2 \mathrm{n}=18$ as putative parental species and is partly or completely sterile $[4,6]$. The hybrid nature of specimens from Poland was estimated from morphological features [5]. To confirm the hybrid origin of specimens newly found in NE Poland site, pollen viability (stainability), diameter, exine sculpture and achene characters were analyzed. The indirect and quick method to estimate meiotic disturbances is pollen viability (stainability) established by histochemical tests $[24,25]$. Non-stained, degenerated, dwarf, differing in size (very small and giant) pollen clearly indicates abnormal male meiosis [24]. Reduced pollen viability and pollen grains with a wide range of diameter were observed in hybrids between different Viola species [17-20]. Frequency of stainable pollen grains is not enough to estimate pollen viability and should be combined with pollen sizes (diameter) because stained pollen grains might be of different size, thus indicating that they are cytologically imbalanced [26].

Based on two different tests, acetocarmine and Alexander, we established that both putative parental species, S. canadensis and S. virgaurea had highly stainable pollen with median values $98.45 \%$ and $98.09 \%$, respectively in acetocarmine test and $99.15 \%$ and $99.33 \%$ in Alexander staining. Both tests indicated evidently reduced pollen stainability in natural

Tab. 1 Pollen viability (stainability) of Solidago taxa by two staining tests.

\begin{tabular}{|c|c|c|c|c|c|c|c|c|}
\hline \multirow[b]{3}{*}{ Taxon } & \multirow{3}{*}{$\begin{array}{l}\text { No. of flowers/ } \\
\text { No. of pollen } \\
\text { grains analyzed }\end{array}$} & \multicolumn{7}{|c|}{ Pollen viability (\%) } \\
\hline & & \multicolumn{3}{|c|}{ Acetocarmine } & \multicolumn{3}{|c|}{ Alexander dye } & \multirow[b]{2}{*}{$P$} \\
\hline & & $\min$ & $\max$ & median & $\min$ & $\max$ & median & \\
\hline S. canadensis & $32 / 6209$ & 93.80 & 99.59 & $98.45^{\mathrm{a}}$ & 97.66 & 100.00 & $99.15^{\mathrm{a}}$ & 0.084 \\
\hline S. virgaurea & $32 / 8242$ & 94.87 & 98.89 & $98.09^{\mathrm{a}}$ & 96.84 & 100.00 & $99.33^{\mathrm{a}}$ & 0.375 \\
\hline S. $\times$ niederederi & $40 / 4947$ & 52.34 & 72.26 & $64.55^{\mathrm{b}}$ & 36.33 & 74.71 & $64.91^{\mathrm{b}}$ & 0.019 \\
\hline
\end{tabular}

Values bearing different letters along one column differ significantly and indicate differences among taxa at $P=0.05$. $P$ values are given for tests' comparisons. 


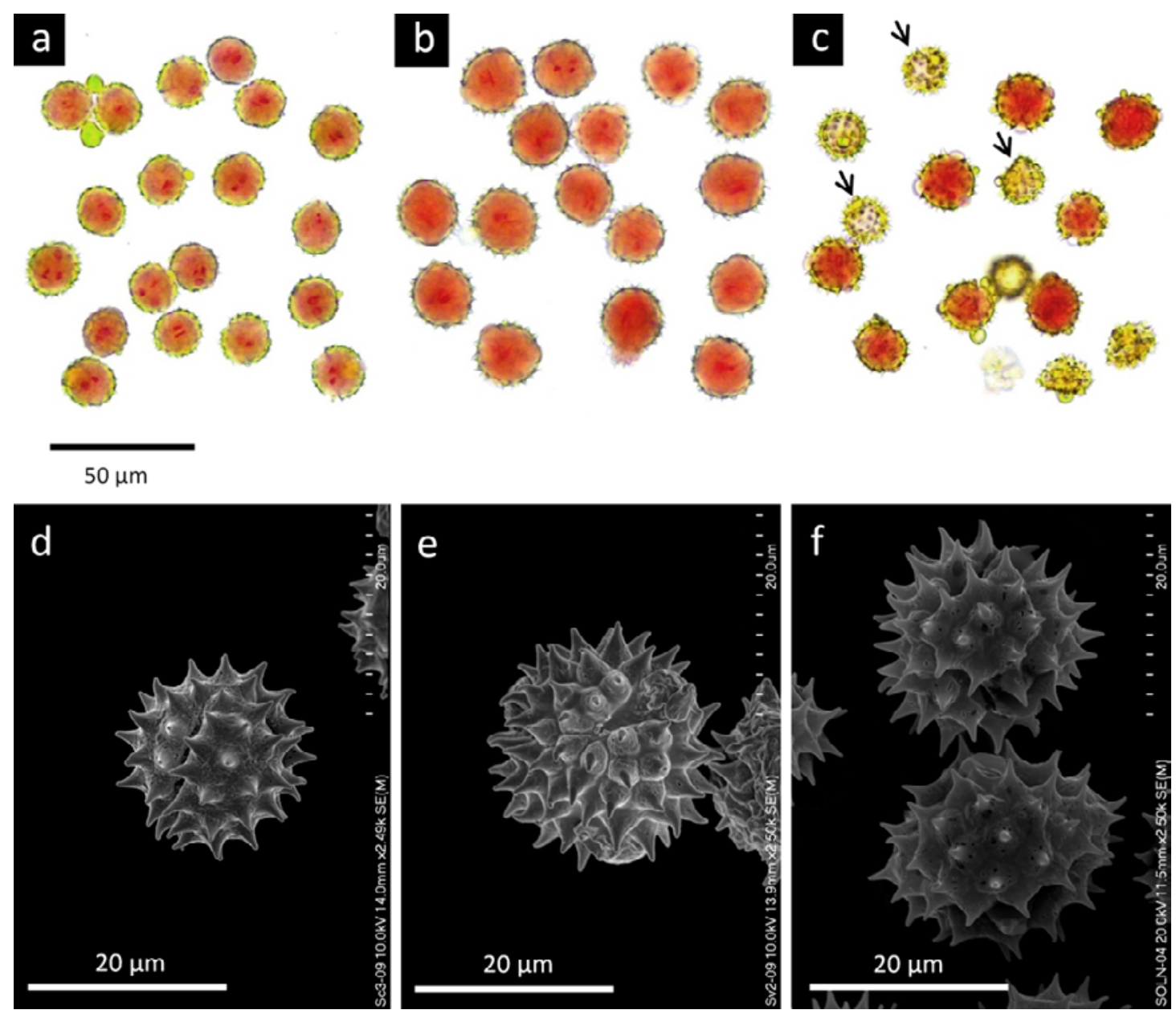

Fig. 1 Pollen grains of Solidago taxa stained with acetocarmine $(\mathbf{a}-\mathbf{c})$ and in the SEM images $(\mathbf{d}-\mathbf{f})$. Solidago canadensis $(\mathbf{a}, \mathbf{d})$, S. virgaurea $(\mathbf{b}, \mathbf{e})$, S. $\times$ niederederi $(\mathbf{c}, \mathbf{f})$. Non-stainable pollen grains marked with arrows $(\mathbf{c})$. Bar in $\mathbf{a}$ corresponds to $\mathbf{b}$ and $\mathbf{c}$.

hybrid S. ×niederederi (median value $64.55 \%$ - acetocarmine test, $64.91 \%$ - Alexander staining; Tab. 1, Fig. 1a-c). There was a significant difference in pollen size (diameter) between two putative parental species. Pollen grains of S. canadensis were smaller $(19.52 \mu \mathrm{m})$ than $S$. virgaurea $(23.48 \mu \mathrm{m})$ but similar in exine sculpture as observed in SEM (Tab. 2, Fig. 1a,b,d,e). Hybrid pollen size (diameter) ranged from $15.30 \mu \mathrm{m}$ to $25.78 \mu \mathrm{m}$ (median $21.11 \mu \mathrm{m}$; Tab. 2, Fig. 1c,f). Pollen grains of all examined taxa observed in SEM were isopolar, 3-aperturate with circular equatorial outline and echinate ornamentation. Solidago canadensis grains had sunken apertures, while those of $S$. virgaurea had colporate

Tab. 2 Pollen size of Solidago taxa.

\begin{tabular}{lcccc} 
& \multirow{2}{*}{$\begin{array}{c}\text { No. of flowers/ } \\
\text { No. of pollen }\end{array}$} & \multicolumn{3}{c}{ Pollen diameter $(\boldsymbol{\mu m})$} \\
\cline { 3 - 5 } Taxon & grains analyzed & min & max & median \\
\hline S. canadensis & $32 / 500$ & 17.11 & 23.24 & $19.52^{\mathrm{a}}$ \\
S. virgaurea & $32 / 500$ & 19.59 & 26.61 & $23.48^{\mathrm{b}}$ \\
S. $\times$ niederederi & $40 / 500$ & 15.30 & 25.78 & $21.11^{\mathrm{a}}$ \\
\hline
\end{tabular}

Values bearing different letters differ significantly and indicate differences among taxa at $P=0.05$. apertures. Hybrid pollen grains seemed to have rather sunken apertures [27].

In the inflorescences of $S$. canadensis and S. virgaurea the frequency of normally developed achenes was very high reaching $90 \%$ and $89 \%$, respectively but they differed in size. Achenes of $S$. canadensis reached $1.52 \mathrm{~mm}$, in S. virgaurea $3.14 \mathrm{~mm}$ (Tab. 3, Fig. 2). Achene development in hybrids was dramatically reduced, in that only 6 achenes of 100 analyzed were normal, while the rest were empty and deformed (Fig. 2d). The length of 6 measured achenes ranged from $1.11 \mathrm{~mm}$ to $2.47 \mathrm{~mm}$ (Tab. 3).

Tab. 3 Achene size of Solidago taxa.

\begin{tabular}{lcccccc}
\hline & $\begin{array}{c}\text { No. of achenes } \\
\text { analyzed/ } \\
\text { Tof normal } \\
\text { Tachenes }\end{array}$ & $\begin{array}{c}\text { No. of } \\
\text { achenes }\end{array}$ & measured & min & max & median \\
\hline S. canadensis & $100 / 90$ & 50 & 0.99 & 1.52 & $1.27^{\mathrm{a}}$ \\
S. virgaurea & $100 / 89$ & 50 & 2.43 & 3.14 & $2.80^{\mathrm{b}}$ \\
S. $\times$ niederederi & $100 / 6$ & 6 & 1.11 & 2.47 & $2.15^{\mathrm{c}}$ \\
\hline
\end{tabular}

Values bearing different letters differ significantly and indicate differences among taxa at $P=0.05$. 


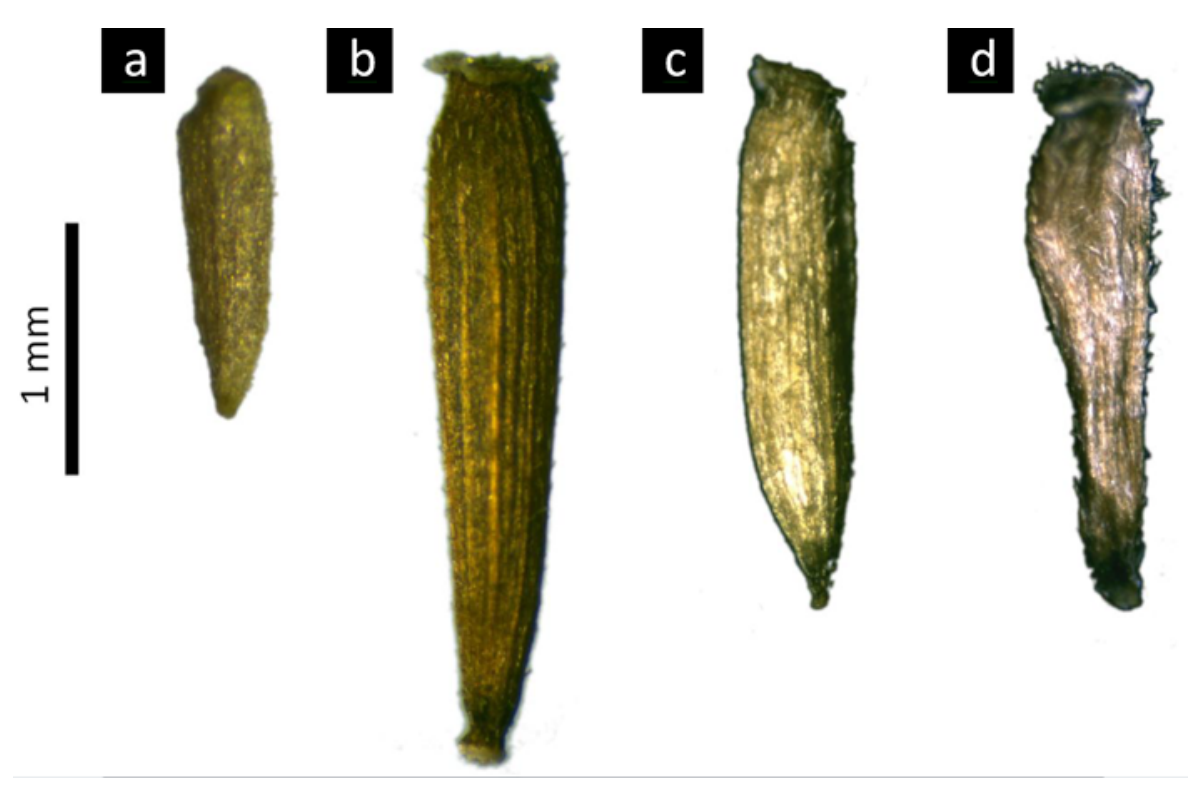

Fig. 2 Achenes without pappus of Solidago canadensis (a), S. virgaurea (b) and S. ×niederederi (c,d); well developed achene (c) and empty achene (d).

\section{Conclusion}

Pollen grain characters (pollen stainability, pollen diameter) and achene development confirmed the hybrid origin of specimens from the newly found locality in Poland and based on morphological characters they could be recognized

\section{Acknowledgments}

Authors would like to thank Professor Elżbieta Kuta from Jagiellonian University for invaluable help in writing this article, for fruitful discussion and valuable suggestions. We are also grateful to Professor Douglas Zook from Boston University for critical reading of the manuscript and English corrections. This work was funded by Jagiellonian University financial support of young scientists (project No. K/DSC/00810).

\section{Authors' contributions}

The following declarations about authors' contributions to the research have been made: acquisition, interpretation and documentation of light and scanning electron microscopy data, statistical analysis of data, drafting of the manuscript: GM; acquisition of light microscopy data: JK; collection of plant material, drafting of the manuscript: AP; statistical analyses, critical revision of the manuscript: AS; studies conception, interpretation of data, critical revision of the manuscript: MKP. All authors made substantial contribution to studies conception and design, data acquisition, statistical analysis, drafting the manuscript and its critical revision.

\section{References}

1. Daehler CC, Carino DA. Hybridization between native and alien plants and its consequences. In: Lockwood JL, McKinney ML, editors. Biotic homogenization. New York, NY: Kluwer Academic/Plenum Publishers; 2001. p. 81-102. http://dx.doi.org/10.1007/978-1-4615-1261-5_5

2. Pyšek P, Richardson DM, Rejmánek M, Webster GL, Williamson M, Kirschner J. Alien plants in checklists and floras: towards better communication between taxonomists and ecologists. Taxon. 2004;53(1):131-143.

3. Khek E. Floristisches aus Ober-Oesterreich. Allg Bot Z Syst. 1905;11(2):21-23. as $S$. $\times$ niederederi, a natural hybrid between $S$. canadensis and $S$. virgaurea.

Further studies on hybrids from other localities in Poland should be analyzed using similar characters, but also its hybrid origin should be confirmed using molecular markers.

4. Nilsson A. Spontana gullrishybrider (Solidago canadensis $\times$ virgaurea) I sverige och Danmark. Sven Bot Tidskr. 1976;70:7-16.

5. Pliszko A. A new locality of Solidago $\times$ niederederi Khek (Asteraceae) in Poland. Biodiv Res Conserv. 2013;29(1):57-62. http://dx.doi. org/10.2478/biorc-2013-0008

6. Burton R. Solidago $\times$ niederederi Khek in Britain. Watsonia. 1980;13(2):123-124.

7. Melzer H. Neues zur Flora der Steiermark, XXVI. Mitt Naturwiss Ver Steiermar. 1984;114:245-260.

8. Melzer H. Neues zur Flora der Steiermark, XXVII. Mitt Naturwiss Ver Steiermar. 1985;115:79-93.

9. Leute GH. Neue und bemerkenswerte Pflanzenfunde im Bereich der Landeshauptstadt Klagenfurt in Kärten II. Carinth II. 1988;96:355-396.

10. Melzer H. Neues zur Flora der Steiermark, XXIX. Mitt Naturwiss Ver Steiermar. 1987;117:89-104.

11. Sunding P. Naturalized Solidago (golden rod) species in Norway. Blyttia. 1989;47(1):23-27.

12. Leute GH. Neue und bemerkenswerte Pflanzenfunde im Bereich der Landeshauptstadt Klagenfurt in Kärten VI. Carinthia: Rudolphinum Jb Landesmus; 2002.

13. Bleeker W, Schmitz U, Ristow M. Interspecific hybridisation between alien and native plant species in Germany and its consequences for native biodiversity. Biol Conserv. 2007;137(2):248-253. http://dx.doi. org/10.1016/j.biocon.2007.02.004

14. Werner PA, Gross RS, Bradbury IK. The biology of Canadian weeds: 45. Solidago canadensis L. Can J Plant Sci. 1980;60(4):1393-1409. http://dx.doi.org/10.4141/cjps80-194

15. Semple J, Cook R. Solidago Linnaeus. In: Flora of North America 
Committee, editor. Flora of North America. Oxford: Oxford University Press; 2006. p. 107-166.

16. Singh R. Plant cytogenetics. 2nd ed. Boca Raton, FL: CRC Press; 2003.

17. Kuta E. Cyto-embryological studies on the species of the Viola L. genus; Nominium Ging. section from the territory of Poland. Fragm Flor Geobot. 1978;24:23-91.

18. Kuta E. Further cyto-embryological studies on Viola L., section Viola L. Acta Biol Cracov Ser Bot. 1981;23:69-82.

19. Kuta E. Embryological observations on two Canadian species of the Viola L. genus (section Plagiostigma Godr). Acta Biol Cracov Ser Bot. 1988;30:39-50.

20. Kuta E. Biosystematic studies on the genus Viola L.; section Plagiostigma Godr. II. Embryological analysis of V. epipsila Ledeb.; V. palustris L. and their hybrids from Poland. Acta Biol Cracov Ser Bot. 1990;31:46-62.

21. Stace CA. Taksonomia roślin i biosystematyka. Warsaw: Polish Scientific Publishers PWN; 1993.

22. Stuessy TF. Plant taxonomy. New York, NY: Columbia University Press; 2008.
23. Góralski G, Lubczyńska P, Joachimiak AJ. Chromosome number database [Internet]. 2009 [cited $2014 \mathrm{Feb}$ 10]; Available from: http:// www.binoz.uj.edu.pl:8080/chromosomes/

24. Dafni A, Firmage D. Pollen viability and longevity: practical, ecological and evolutionary implications. In: Dafni A, Hesse M, Pacini E, editors. Pollen and pollination. Vienna: Springer; 2000. p. 113-132. http:// dx.doi.org/10.1007/978-3-7091-6306-1_6

25. Słomka A, Kawalec P, Kellner K, Jędrzejczyk-Korycińska M, Rostański A, Kuta E. Was reduced pollen viability in Viola tricolor $\mathrm{L}$. the result of heavy metal pollution or rather the tests applied? Acta Biol Cracov Ser Bot. 2010;52(1):123-127. http://dx.doi.org/10.2478/v10182-010-0016-6

26. Słomka A, Bohdanowicz J, Poznańska E, Kwiatkowska M, Pilarska $\mathrm{M}$, Struebig $\mathrm{M}$, et al. Usefulness and limitations of pollen characters in environmental studies based on Viola L. species (sect. Melanium Ging.). Mod Phytomorphology. 2014;5:31-34.

27. Halbritter H, Weber M, Zetter R, Frosch-Radivo A, Buchner R, Hesse M. Pollen terminology: an illustrated handbook. Vienna: Society for the Promotion of Palynological Research in Austria; 2008. 